URI : http://hdl.handle.net/11298/47

\title{
Papel de los medios comunicación social
} de

Edith Vaquerano de Portillo

Docente Investigadora, Escuela de Comunicaciones de la UTEC

\section{Resumen}

Los jóvenes universitarios salvadoreños tienen una cultura de consumo de medios muy fuerte. La televisión es su medio preferido, aunque con una presencia muy importante de la Internet y del gusto por las producciones internacionales.

\section{Palabras claves:}

Valores, cultura de consumo, medios de comunicación, programas, influencia

\section{Introducción}

i Qué relevancia puede tener el conocer qué medios y espacios o programas consumen los jóvenes? En realidad, mucha si se acepta primero que las sociedades enfrentan crisis en diferentes ámbitos, algunas de las cuales se atribuyen a la influencia que los medios de comunicación ejercen en ellas, incluso como transmisores de valores y pautas de conducta, más allá del alcance que en este campo puedan tener las instituciones educativas tradicionales. A partir de ahí, surgen iniciativas en la línea de que, si los medios son cada vez más omnipresentes, lo que conviene es dejar de reducirlos a simples medios de información y preparar la escuela para proporcionar técnicas de aprendizaje, autoexpresión y participación (Gutiérrez, 1972).

\section{Educación en valores \\ y medios de comunicación}

La comunidad internacional ha definido que la educación debe orientarse a que los estudiantes aprendan a conocer, a hacer, a ser y a convivir con los demás. En ese contexto, se inserta el tema de la educación en valores, que supone un modelo de aprendizaje ético, que tenga como fin, la transformación del entorno de cara al logro de mayores niveles de felicidad, libertad y equidad para todos (Martínez, 2004). Se dice que educar en valores es tratar de crear condiciones para que las personas sean capaces de apreciarlos y para hacerlo; la visión de integrarlos como ejes transversales es una de las más aceptadas, por cuanto "debe ser parte de los objetivos de cada asignatura $y$ deben fomentarse a través de las diferentes disciplinas académicas que cursa el estudiante" (Esper, 2007, p.92).

Para Ortega y Mínguez (2001), si bien es cierto la familia es el medio por excelencia para el aprendizaje de valores, no constituye el único medio socializador $y$, por el contrario, califica como incorrecto separar familia, escuela y sociedad. Martínez (2004) afirma también categóricamente que la acción de educar en valores no puede limitarse a la escuela. “El aprendizaje social, la imitación de modelos, y las enseñanzas de valores que la familia, la vida cotidiana y los medios de comunicación en especial generan, son procesos que contribuyen a nuestro aprendizaje ético" (Martínez, 2004, p. 36).

Se perfila ya la asignación de un papel preponderante en la formación en valores a los medios de comunicación social. Es tal el interés que generan, que la misma Iglesia Católica, por medio del Pontificio Consejo para las Comunicaciones Sociales (2000), ha considerado prudente pronunciarse sobre la ética en las comunicaciones sociales. Así, al tiempo que reconoce el alcance y diversidad de los medios de comunicación social, les señala tanto aportes como abusos económicos, políticos, culturales, educativos y religiosos. Sin embargo, aun 


\section{Abstract}

Salvadoran university students have strong media consumption culture, television is their preferred medium, although there is very important presence of the Internet and the taste for international productions.

\section{Key words:}

Values, consumer culture, media, programs, influence.

reconociendo el poder que estos tienen, concluye que no son más que medios, instrumentos o herramientas que pueden ser utilizados con buenos o malos fines y que la responsabilidad, y la decisión, por lo tanto, recae en las personas.

\section{Educación para los medios}

La escuela debe sin duda adaptarse a esta realidad e impulsar una pedagogía crítica de los medios, educación en medios o educación para la recepción, términos que, en su esencia, se refieren a dotar a los individuos de un consumo crítico de los contenidos que ofrecen los medios de comunicación. Fecé (2000) centra su atención en la lectura crítica de los medios audiovisuales, particularmente sosteniendo que, contrario a lo que muchos autores sostienen, no actúan como espejos de la realidad y que, por el contrario, producen construcciones de la realidad, por lo que "la enseñanza de los medios audiovisuales no se puede entender $\sin$ el complemento de otras acciones: las audiencias, estructura y funcionamiento de las industrias de comunicación, las prácticas periodísticas y el uso estético o creativo de los medios" (Tyner, 1996, citado en Fecé, 2000, p. 141).
En este contexto, la escuela como institución tiene ante sí la posibilidad de construir nuevas relaciones con los medios de comunicación ya que, como bien señala Buckingham, (2005), los medios representan un "nuevo" ambiente de aprendizaje, un tipo de escolaridad informal que, para los jóvenes, resulta mucho más atractiva que la obligatoria y aburrida aula tradicional. Lo que se propone es una educación en medios, que potencie en el estudiante tanto sus capacidades críticas como las creativas y que constituye, en sí misma, preparación para los medios y no protección de ellos. El modelo de aprendizaje mediático que se propone es un proceso que parte de comprometer a los estudiantes a convertir su conocimiento implícito previo en explícito; capacitarlos luego para sistematizar ese conocimiento y generalizar a partir de él $y$, finalmente, estimularlos a cuestionar, ampliar y superar ese conocimiento (Buckingham, 2005).

La adquisición de sentido crítico es inherente a un proyecto de educación en medios, sin soslayar que es una cualidad que se aprende con la práctica y que, si bien es cierto se centra en el alumno, implica una fuerte demanda para el docente: de ser crítico consigo mismo, de las prácticas comunicativas que utiliza, de los métodos y recursos didácticos que emplea (Charles, 1990). En otras palabras, el sentido crítico debe ser adquirido primero por el docente. Si el centro del proceso es el estudiante, ahí está entonces el punto de partida. Si se le va a educar en medios de comunicación, hay que identificar primero sus hábitos y preferencias

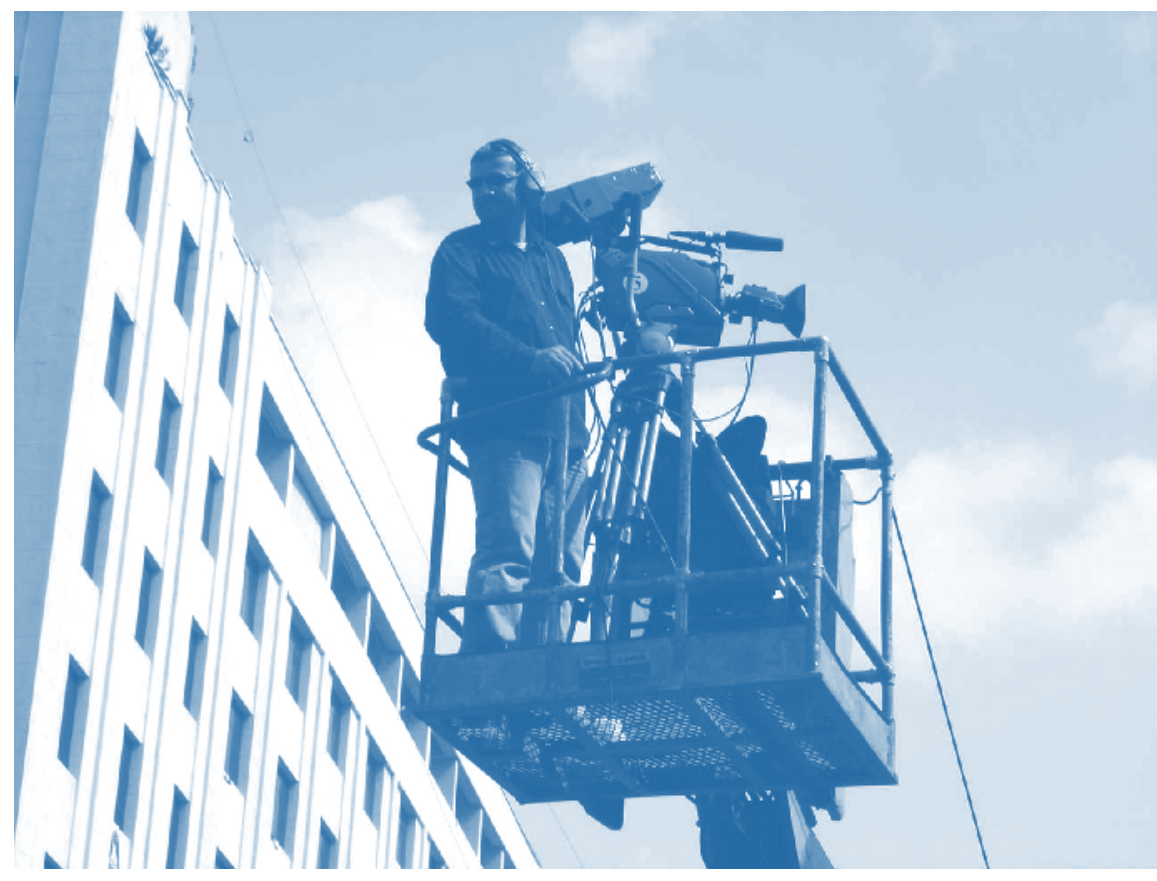




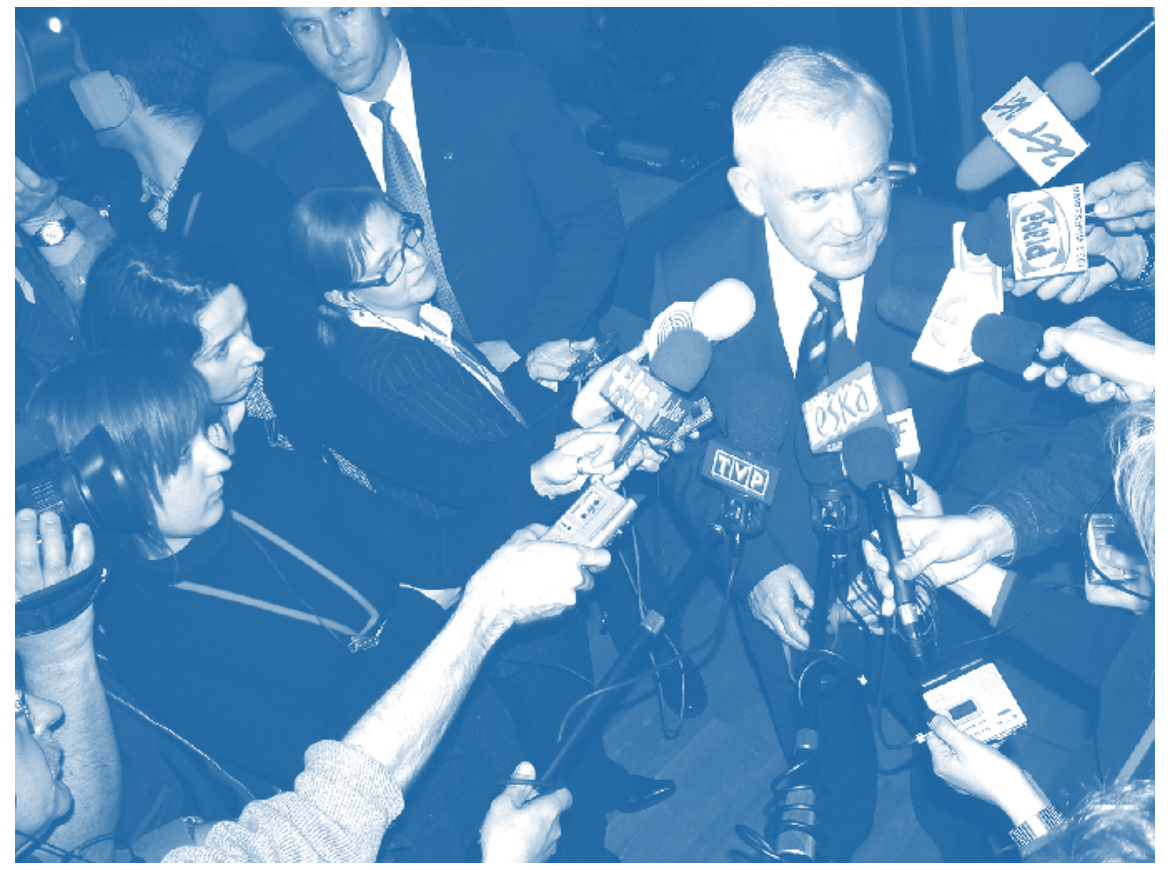

mediáticas, así como las valoraciones que hacen sobre los medios que consumen.

\section{Objetivos y sujetos de estudio}

Esta investigación, realizada a través de una encuesta, pretendía identificar hábitos y preferencias mediáticas de los jóvenes universitarios salvadoreños, así como las valoraciones que hacen acerca del aprendizaje que el consumo de estos medios les deja. Como participantes del estudio se seleccionaron 658 estudiantes de ambos géneros, de entre 17 y 28 años de edad, de ocho universidades del área metropolitana de San Salvador, incluyendo la estatal y siete privadas que, en conjunto, ofrecen una amplia oferta académica en diversos campos del conocimiento y atienden diferentes sectores socioeconómicos. Los estudiantes fueron seleccionados aleatoriamente $y$ abordados en entrevistas personales en sus respectivos centros de estudio. La distribución de cuotas para cada universidad se hizo de acuerdo con la población estudiantil de cada una de ellas, respetando el criterio de proporcionalidad.

\section{Hábitos y preferencias mediáticas}

Sin duda alguna, los medios de comunicación ocupan una posición de primer orden en la vida de los jóvenes universitarios, especialmente la televisión y la Internet, a los que estarían dedicando en conjunto, al menos cuatro y hasta ocho horas por motivación para su consumo el ocio o búsqueda de entretenimiento; es un hecho que, en general, no buscan en No es de extrañar entonces tampoco que la programación de los medios responda a esas motivaciones, en la medida enque ofrecen lo que sus día en total, teniendo como principal los medios educación ni información. públicos demandan, lo que, a su vez, les garantiza la subsistencia y la bonanza económica por la contratación de espacios con fines publicitarios.

Estos hábitos de consumo de medios y las preferencias que los jóvenes expresan por determinados tipos de espacios y sitios, predominantemente extranjeros, están marcados por los avances tecnológicos y la interactividad que propician, que han permitido que las barreras culturales se vuelvan cada vez más débiles y se tenga acceso muy fácil a manifestaciones de patrones de conducta propios de otras latitudes y culturas, que la naturaleza rebelde de los jóvenes estaría más dispuesta a aceptar y asumir, incluso por el simple hecho de tener la oportunidad de ir contra el orden establecido.

Es evidente que, al menos entre los jóvenes universitarios, que de por sí son parte de una élite al tener la posibilidad de acudir a un centro de estudios superiores, el gusto por lo extranjero abre las puertas a procesos de transculturización, que resulta imposible detener. Lo contradictorio es que, por un lado, se les cuestione a esos mismos jóvenes la adopción de visiones de la vida y pautas de conducta ajenas a su entorno, al tiempo que, desde la familia y la escuela, entendida en su carácter institucional, se le insta a prepararse para los retos de los nuevos tiempos, de los que la globalización y los acelerados avances tecnológicos son elementos fundamentales.

No puede soslayarse tampoco que sibien la televisión por cable, preferida de los jóvenes y cada vez más a su alcance dada la competencia entre diferentes compañías operadoras del 
servicio, ofrece un amplia gama de opciones, sin duda superior a la de la señal abierta; al final es una opción limitada por cuanto tiene un número determinado de canales, además de la barrera que el idioma sigue representando cuando no se cuenta con el recurso de los subtítulos en español. Sin embargo, las opciones en Internet pueden calificarse como infinitas y las posibilidades de "censura" son mínimas, por cuanto no hay manera de que se pueda mantener permanentemente alejados a los jóvenes de estímulos que puedan considerarse negativos para ellos.

Por otro lado, la pregunta quizás debería ser si los jóvenes cuentan o no con el criterio suficiente para separar la ficción de la realidad, para identificar el punto exacto en que se encuentra la línea entre lo que es correctoylo incorrecto, lo que también es sujeto de discusión por tratarse de valoraciones totalmente personales y por tanto, subjetivas. Se entra en este punto en el tema de los valores que, entendidos como los principios y los fines que fundamentan y guían el comportamiento humano pueden, también, dar pie a discusiones si se toma en cuenta que se considera que no existen por sí mismos, sino que son cualidades de las cosas u objetos, que dependen del juicio que sobre ellos se tenga.

Motivo deatención en los resultados es la preferencia manifiesta en Internet por los llamados sitios académicos, que debería ser totalmente lógico tratándose de un estudio con estudiantes universitarios, pero que quienes trabajan en la docencia saben que han llevado a los estudiantes a la práctica de una cultura del mínimo esfuerzo y del fraude. Lejos de utilizarlos como fuentes de consulta y apoyo para la discusión y generación de conocimiento, se han convertido en el almacén donde se obtienen "tareas a la medida" con simplemente cortar y pegar, sin que les cause ningún conflicto ético atribuirse el trabajo de otros, acto que en sí mismo es signo de deshonestidad y falta de integridad. Esta habitual práctica debería preocupar y llamar a las universidades a tomar medidas concretas para enfrentarla y erradicarla. Si en la universidad se forma a las nuevas generaciones de políticos, empresarios y profesionales que eventualmente marcarán el rumbo de una nación, qué garantías se tienen de que quien acudió a prácticas deshonestas como estudiante no lo hará luego como funcionario, director o gerente.

Los resultados apuntan también a una baja incidencia de la radio en la

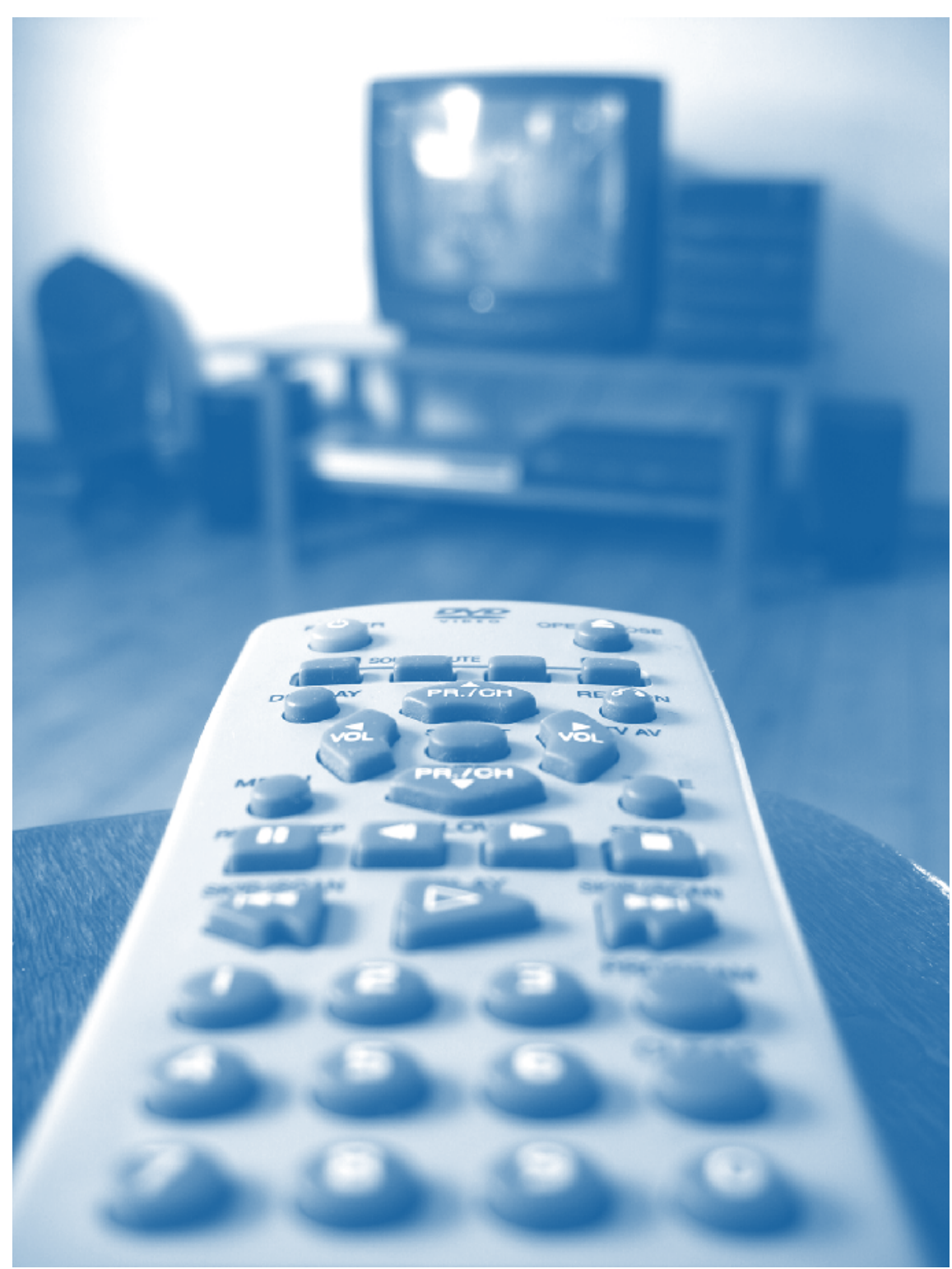


vida y gustos de los jóvenes, lo que, de alguna manera, es coherente con la calidad de medio de compañía y condición de fugacidad que el medio tiene. Lo que sí debería ser motivo de preocupación es la ausencia de hábitos de lectura en los jóvenes, ya que si no leen al menos los periódicos, mucho menos estarán dispuestos a hacerlo con textos más elaborados, que son los que deberían estar utilizando como apoyo en su proceso de aprendizaje en la universidad, y no conformarse con la simple lectura pasajera de folletos $y$ apuntes de clase, lo que sumado al recurso del plagio con base en Internet, estaría afectando la calidad de la formación que se supone están adquiriendo.

Al mismo tiempo, son dignas de atención las valoraciones que los encuestados hacen sobre el aprendizaje que les dejan los medios, por cuanto aun y cuando la mitad lo califican positivamente, existe también la capacidad de reconocer que una actividad a la que dedican una tercera parte del día, no les deja ningún aprendizaje, incluyendo a los que se abstuvieron de emitir juicio al respecto, pero tampoco se atrevieron a calificarlo favorablemente. Este sería un signo alentador en tanto refuerza que el consumo de medios, por parte de los jóvenes, busca simple entretenimiento y estarían siendo capaces de reconocer lo que obtienen a cambio.

\section{A manera de conclusión}

Si existe entonces una fuerte cultura de consumo de medios - principalmente extranjeros- por parte de los jóvenes, lo cual, lejos de disminuir apunta a aumentar, especialmente en el caso de Internet, las preocupaciones por los efectos que estos medios tienen en ellos -positivos o negativos- deberían llevar las preguntas pendientes de respuesta, quellamana profundizaren el conocimiento de las motivaciones

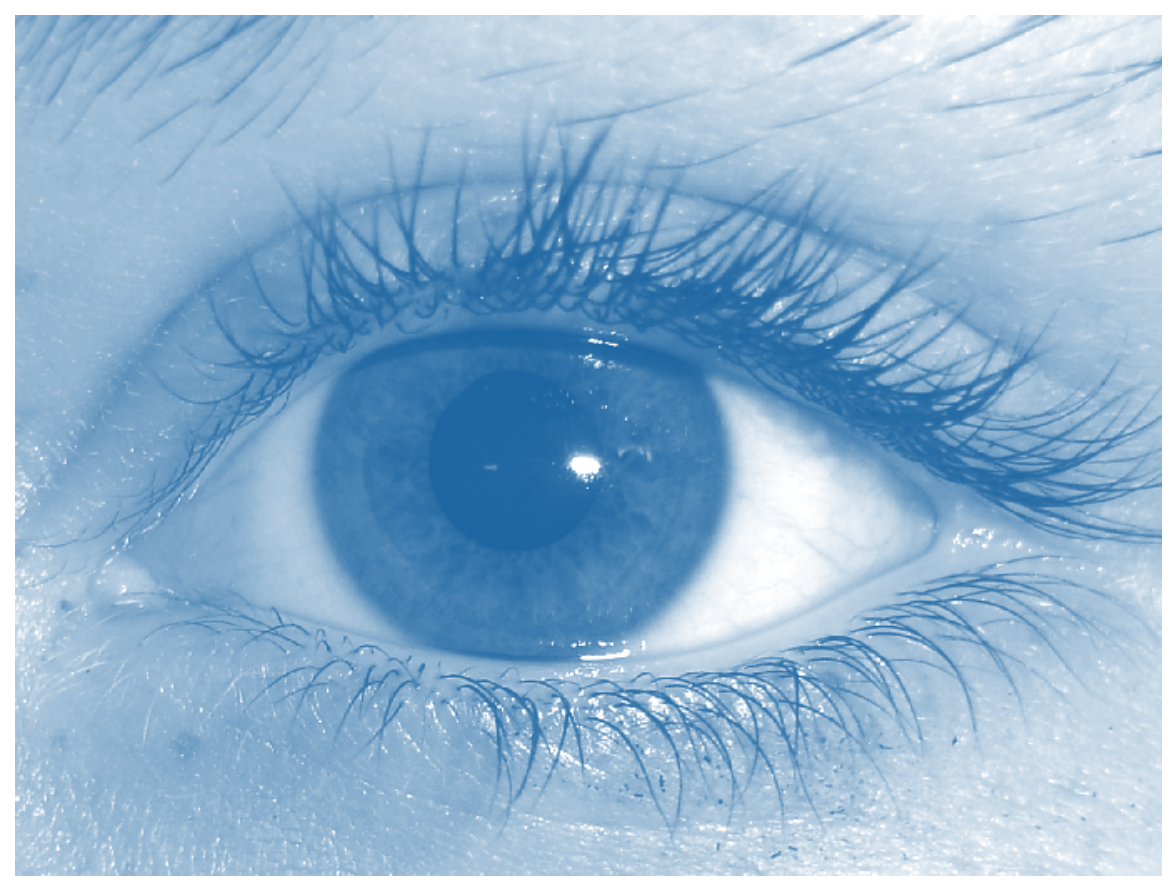

$4 c$ Lo que sí debería ser motivo de preocupación es la ausencia de hábitos de lectura en los jóvenes, ya que si no leen al menos los periódicos, mucho menos estarán dispuestos a hacerlo con textos más elaborados, que son los que deberían estar utilizando como apoyo en su proceso
de aprendizaje en la
universidad.

que inciden en estas preferencias, así como de la verdadera influencia - si es que la tienen- en el pensamiento y la conducta cotidianos de ellos. Con esa información, como punto de partida, debería ser factible aspirar a que las instituciones educativas $y$ cuerpo docente, definan estrategias para que los estudiantes "aprendan de los medios" y no "por los medios" (González, 2000), lo que pasa por la adquisición de sentido crítico, primero por parte del docente, y luego por el estudiante (Charles, 1990).

Pero este ejercicio de reconversión no puede - ni debe- ser producto de la casualidad. Para los centros educativos, implica realizar un ejercicio de autorreflexión acerca de sus funciones, siendo en sí mismos espacios de libertad, abiertos al medio y a sus cambios. Para el docente, significa asumir un compromiso personal derivado de la convicción y fortalecido con la formación para tal fin. En cuanto al estudiante, receptor de este proceso, lo que se impone es conocerlo y comprenderlo. $\mathrm{Y}$ 
en este punto, es innegable que la brecha generacional entre docentes y estudiantes que, a su vez, incide en otro tipo de brecha tecnológica o analfabetismo informático, es determinante.

$\mathrm{Si}$ se quiere educar para los medios, los docentes deben, al menos, conocer esos medios y lo que ofrecen a los jóvenes. Se impone trascender la crítica y censura de lo que incluso ni se conoce. Este estudio apenas esboza cuáles son los

\section{Bibliografía}

- Buckingham, D. (2005). Educación en medios. Alfabetización, aprendizaje y cultura contemporánea. Barcelona, España: Paidós.

- Charles, M. (1990). Educación para la recepción. Hacia una lectura crítica de los medios (Ed.). Aparato escolar y medios de comunicación (pp. 68-81). México Editorial Trillas.

- Esper, M. (2007). ¿Cómo educar en valores éticos? Barcelona, España: Paidós. México Editorial Trillas.

- Fecé, J. (2000). Comunicación y educación en la sociedad de la información. Nuevos lenguajes y conciencia crítica (Ed.), Lectura crítica de medios audiovisuales (pp. 135-168). Barcelona, España Editorial Paidós.

- González, J. (2000). Comunicación y educación en la sociedad de la información. Nuevos lenguajes y conciencia crítica (Ed.). Variables de la educación en comunicación medios que los jóvenes consumen. EI siguiente paso es profundizar en las razones de consumo de medios, en las valoraciones que los estudiantes hacen de ellos como transmisores de valores, así como su influencia en sus patrones de conducta. De la misma manera, es necesario conocer la visión que los docentes universitarios tienen sobre el uso de los medios de comunicación en la formación en valores de sus estudiantes.

(pp. 171-219). Barcelona, España Editorial Paidós.

- Gutiérrez, F. (1972). El lenguaje total. Buenos Aires, Argentina Editorial Hvmanitas.

- Martínez, M. (2004). ¿Qué significa educar en valores hoy? (Ed.) Educar en valores es crear condiciones pedagógicas y sociales (pp. 17-44). Madrid, España Organización de Estados Iberoamericanos para la Educación, la Ciencia y la Cultura (OEI) y Ediciones Octaedro.

- Ortega, P. y Mínguez, R. (2001). La educación moral del ciudadano de hoy. Barcelona, España Paidós Ibérica, S.A.

- Pontificio Consejo para las Comunicaciones Sociales (2000). Ética en las comunicacio-nes sociales. Extraído el 29 de junio del 2009 desde http://www. vatican.va/roman_curia/pontifical_ councils/pccs/documents/rc pc_pccs_doc_20000530_ethicscommunications_sp.html.
Con esa información en mano -y solamente hasta entonces-se puede empezar a hablar de definir las bases y principios de una educación para los medios, de un proceso de definición de propuestas metodológicas para el análisis de los mismos. Después de todo, los medios están ahí, son omnipresentes e inevitables. Desde el ejercicio docente es posible potenciar su papel informativo y educativo, solamente hay que tomar la decisión de hacerlo, conocerlos y utilizarlos.

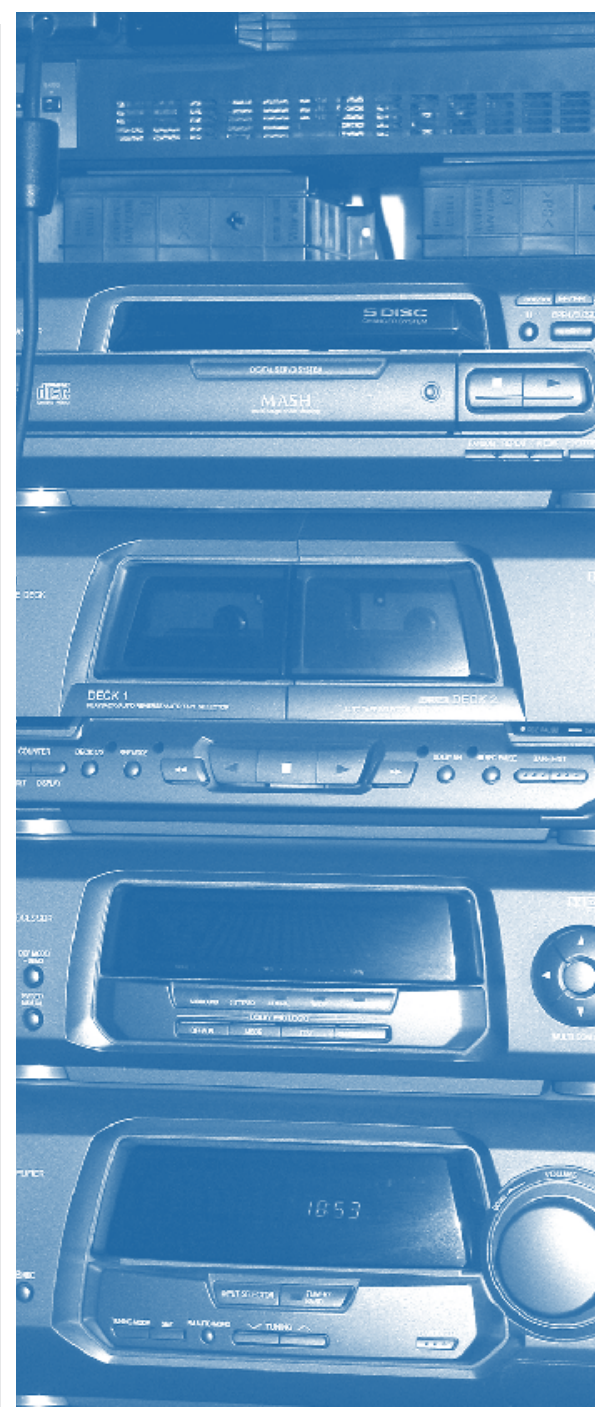

